\title{
Effects of Two-Year Variation in Soil Moisture Condition on the Development of Larch Root System in Eastern Siberia
}

\author{
Chisato Takenaka1 ${ }^{*}$, Mie Miyahara ${ }^{1}$, Takeshi Ohta ${ }^{1}$, Trofim C. Maximov ${ }^{2}$ \\ ${ }^{1}$ Graduate School of Bioagricultural Sciences, Nagoya University, Nagoya, Japan \\ ${ }^{2}$ Plant Ecological Physiology \& Biochemistry Lab, Institute for Biological Problems of the Cryolithozone of the \\ Siberian Division of the Russian Academy of Sciences, Yakutsk, Russia \\ Email: *chisato@agr.nagoya-u.ac.jp
}

Received 29 February 2016; accepted 2 June 2016; published 6 June 2016

Copyright (C) 2016 by authors and Scientific Research Publishing Inc.

This work is licensed under the Creative Commons Attribution International License (CC BY). http://creativecommons.org/licenses/by/4.0/

(c) (i) Open Access

\begin{abstract}
Recent climate changes, including an increase in precipitation, have affected tree physiology in eastern Siberia. We investigated the response of larch to wet and dry soil water conditions in pot experiments using larch seedlings grown under near-natural conditions in eastern Siberia over two growing seasons. Three patterns of wet- and dry-treatment combinations were applied over 2 years: wet treatments in 2006 and 2007 (WW treatment), dry in 2006 and wet in 2007 (DW treatment), and dry in 2006 and 2007 (DD treatment). After 1 year of treatment, no significant difference between the dry and wet treatment was found in root distribution and needle water content, except for the content of abscisic acid in roots. After 2 years of treatment, the DW treatment induced different tendencies in the gas exchange activity and in the needle biomass and root distribution of seedlings in comparison with $\mathrm{WW}$ treatments, despite the same water condition in 2007. We suggest a possibility that seedlings that experience drought stress might store some memory of drought that influences their physiology in the next growing season.
\end{abstract}

\section{Keywords}

Larch, Soil Water Content, Root Distribution, Memory Effect

\section{Introduction}

Climate change has been attracting much attention because of an increase in the frequency and magnitude of ex-

${ }^{*}$ Corresponding author.

How to cite this paper: Takenaka, C., Miyahara, M., Ohta, T. and Maximov, T.C. (2016) Effects of Two-Year Variation in Soil Moisture Condition on the Development of Larch Root System in Eastern Siberia. American Journal of Climate Change, 5, 157-166. http://dx.doi.org/10.4236/ajcc.2016.52015 
treme weather events [1]. According to the IPCC prediction, both precipitation and air temperature will increase in eastern Siberia. The summer precipitation pattern has been yearly changing in eastern Siberia [2] [3]. Ohta et al (2014) [2] reported that the number of living larch decreased in forests by 15\% from 1998 to 2011, and that the annual precipitation pattern was classified into three phases: normal years from 1998 to 2000 and from 2009 to 2011, dry years from 2001 to 2004, and wet years from 2005 to 2008 in eastern Siberia. The unusual waterlogging occurred in wet years is suspected as one cause of recent decline in the larch forest.

Larch, one of the dominant coniferous tree species in eastern Siberia, tolerates large variations in temperature (from $-50^{\circ} \mathrm{C}$ to $30^{\circ} \mathrm{C}$ ) and soil water content (from $5 \%$ to over $40 \%$ ) [2]. Conifer species, such as larch, are evolutionarily more ancient than angiosperms, and their adaptive mechanisms and features are more pronounced [4]. Therefore, elucidating the mechanism of decline of larch in eastern Siberia is important for understanding the limits of tolerance of tree species to coming extreme weather events due to global climate change [5].

In pot experiments with seedlings of Larix gmelinii, a typical larch species in eastern Siberia, we found that the allocation of photosynthetic products to roots and root respiration were lower under wet than those under dry conditions [6]. However, L. leptolepis, a larch of Japanese temperate forests, showed the opposite tendency. These results indicated that the larch species in eastern Siberia adapt to dry environmental condition by increasing their root activity such as elongation and respiration. However, the information from this pot experiment was limited as it was derived only from a single growing season in Aichi prefecture, Japan. Thus, the effects on larch physiology of recurrent dry or wet conditions in the natural environment in eastern Siberia remain unknown.

Recently, many researchers have proposed "stress memories" [7]-[10]. This expression describes the alteration of plant responses following a history of exposure to stress [7]. Most interest has been focused on the physiology of tree species because of their long lifetimes [4] [9] [11]. Yakovlev reviewed on adaptive epigenetic memory in conifer species, especially from the viewpoint of seed production [4], and Brautigam summarized heritable epigenetic marks derived from various environmental stresses in forest trees based on molecular biology [9]. Although data describing epigenetic memories at the molecular level have been accumulated using various model plants, field observations of tree response to recurrent environmental stress are still lacking, especially in eastern Siberia.

The purpose of this study was to characterize the response of larch to wet or dry soil water conditions during multiple years under natural conditions in eastern Siberia. The memory effect of environmental stress in larch trees is discussed.

\section{Materials and Methods}

\subsection{Experimental Site}

The experiment was conducted at the Spasskaya Pad Experimental Forest of the Institute for Biological Problems of the Cryolithozone (62 $\left.15^{\prime} 18^{\prime \prime} \mathrm{N}, 129^{\circ} 37^{\prime} 8^{\prime \prime} \mathrm{E}\right)$ in the Lena river basin, located approximately $20 \mathrm{~km}$ north of Yakutsk, Republic of Sakha, Russia (Figure 1). The mean annual temperature and precipitationare $-10.2^{\circ} \mathrm{C}$ (1961-1990) and $260 \mathrm{~mm}$ (1998-2006, S.D: $82 \mathrm{~mm}$ ) (Ohta et al., 2008), respectively. At this site, the sunrise and sunset times are around 2:30 and 22:30 at the summer solstice and around 6:00 and 18:30 at the autumnal equinox day, respectively. During summer, the depth of the active permafrost layer varies yearly from about $1.2 \mathrm{~m}$ deep (ex. 2006) to over $2.0 \mathrm{~m}$ (ex.2007).

\subsection{Plant Material}

Seedlings of Larix cajanderi, a close relative of L. gmelinii that is dominant in eastern Siberian forests, were collected in the experimental forest. The average height of the collected seedlings was $42.5 \mathrm{~cm}$. For plantation, we used a commercially available seal container $(30 \mathrm{~cm} \times 20 \mathrm{~cm} \times 15 \mathrm{~cm})$ with a soft plastic cover. One small side wall of a container was removed and small holes were opened randomly in the other small side wall. The processed container was used as a plantation box as shown in Figure 2. Each seedling was planted in the box with 7.5 L of soil on May 24, 2006. Soil for planting was prepared by mixing humus soils from the surface layer $(0-5 \mathrm{~cm})$ with mineral soils (deeper than $5 \mathrm{~cm}$ depth) taken from the experimental forest. Soil type in this area is clay mixed with sand layers. One side of the box, which is a soft plastic cover of the container, could be opened for observation of roots. After planting, they were adapted until the start of treatment in a greenhouse built in the experimental forest (Figure 2). 


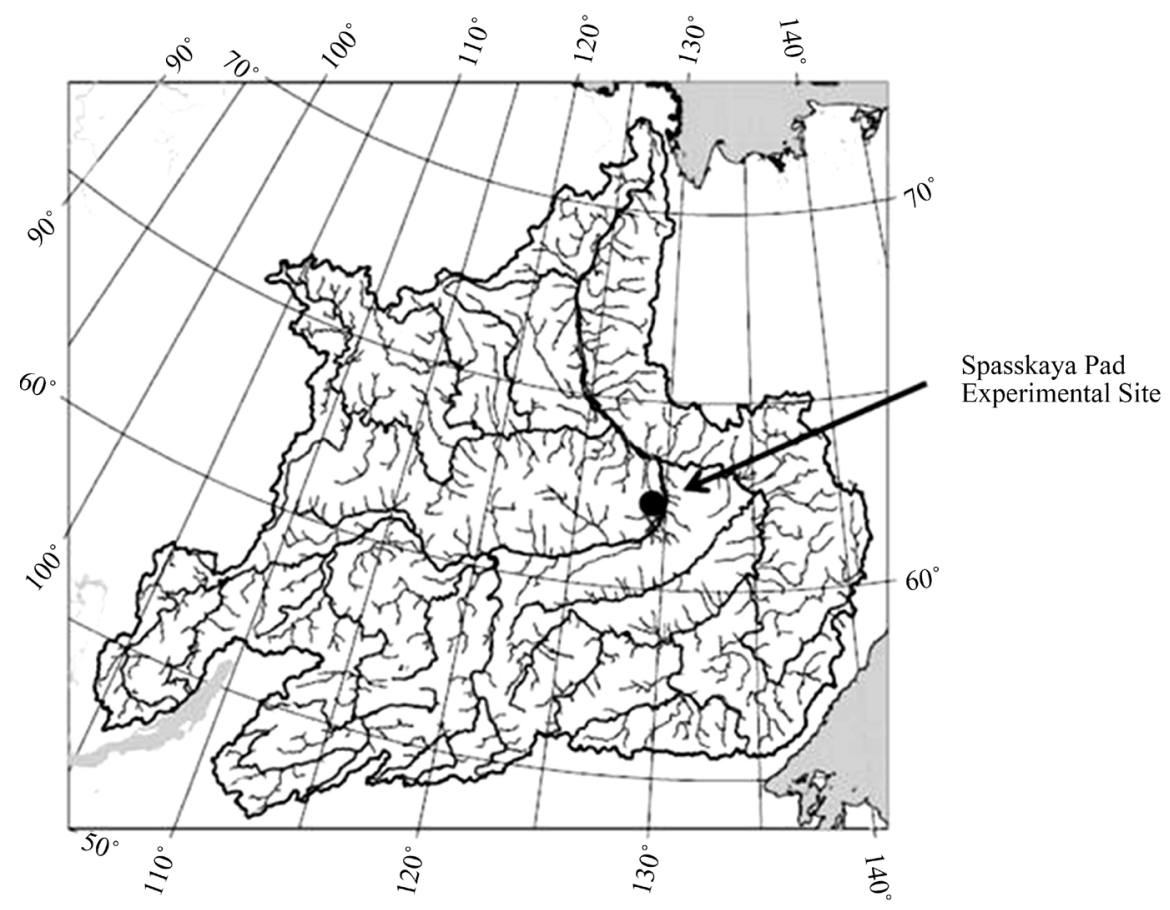

Figure 1. Location of the experimental site. The area shows the Lena river basin.

Watering depth
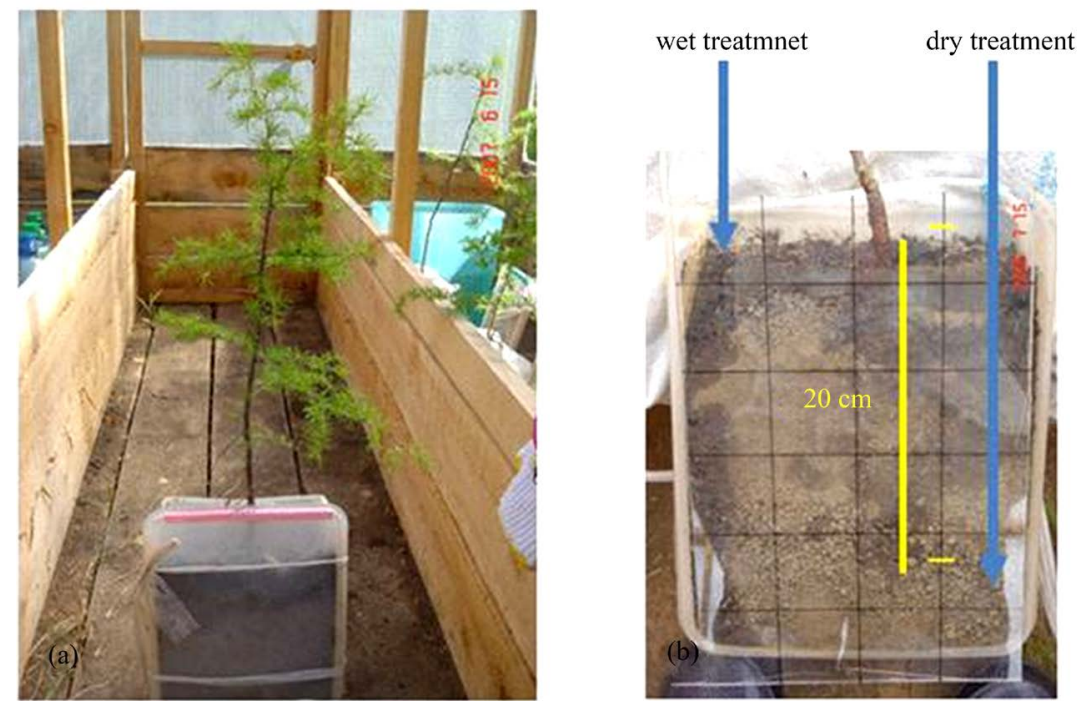

Figure 2. Seedling of Larix cajanderi planted in a plastic box (a) and the watering point for wet and dry treatments (b).

\subsection{Treatment}

Wet and dry treatments were designed. In a wet treatment, water was supplied to the pots from the soil surface every other day during the treatment periods. This treatment mimicked the condition of sufficient precipitation. As a dry treatment, water was supplied to the pots at $20 \mathrm{~cm}$ depth every other day. This treatment imitated the usual dry condition in the surface soil layer observed in eastern Siberia, established by the supply of melt water from the deeper permafrost layer [12]. Three treatment combinations for the 2 years (2006 and 2007) were applied; wet treatments in 2006 and 2007 (WW treatment), dry in 2006 and wet in 2007 (DW treatment), and dry 
in 2006 and 2007 (DD treatment). The treatment periods in the summer season were from July 15 to September 13, 2006 and from June 18 to August 5, 2007. During periods other than those of the watering treatments, no treatment was applied to the seedlings. At each watering, $200 \mathrm{ml}$ of tap water was supplied to a pot using an automatic watering timer (EY4200-H; Electric Industrial Co., Ltd.). At the start of treatment in 2006, 15 seedlings were divided into two groups ( 8 and 7 seedlings) to be their average height almost equal. Seven seedlings were subjected to the watering treatment and eight seedlings were subjected to the dry treatment. Eight seedlings of the dry treatment in 2006 were divided into two groups (4 seedlings each) for DW and DD treatments to be their average height almost equal at the beginning of the treatment in 2007. Then, the numbers of seedlings subjected to the WW, DW, and DD treatments were seven, four, and four, respectively.

The seedlings were grown in a greenhouse with all windows opened during the treatment periods (Figure 3(a)) and closed during the other periods (Figure 3(b)). Thus, the temperature and humidity in the greenhouse were similar to those outside during the treatment periods. The maximum and minimum air temperatures during the experimental term measured at $1.8 \mathrm{~m}$ height in a 32-m-tall meteorological observation tower in the experimental forest site were $31.7^{\circ} \mathrm{C}$ on July 31, 2006 and $-45.6^{\circ} \mathrm{C}$ on January 9, 2007, respectively. The soil moisture under each treatment was monitored at 10 and $30 \mathrm{~cm}$ depth with a time domain reflectometry sensor (EC-10; Logger, Em-5; Decagon devices, Inc.). The measurements of soil moisture in 2006 were performed twice at the beginning of the treatments and after 2 months, and in 2007 it was conducted continuously during the treatment period.

\subsection{Sampling and Measurement}

Root samples were uniformly taken from every depth by opening the side cover of the root box on the middle of August 2006 for analysis of abscisic acid (ABA). The root samples were frozen immediately after the sampling and transported to a laboratory for the analysis. Needle samples were also taken on the same day for measurement of relative water content. At the end of September 2006, the root systems were photographed by opening the side cover of the root box to observe root development. The length of roots appearing in the images was calculated with LIA32 (Yamamoto, 2005). The root length per unit area of cross section was compared between the upper layer (0 - $15 \mathrm{~cm}$ depth) and lower layer (15 - $30 \mathrm{~cm}$ depth) of soil.

On June 17, 30 and July 26, 2007, the photosynthesis rate, stomatal conductance, and transpiration rate of larch needles were measured with a Li-6400 portable photosynthesis system (LICOR Inc., USA). On August 5, 2007, all seedlings were harvested to measure aboveground and root biomass, root length, and root distribution.

Relative water content in needles was determined by measuring the weight of needles before and after oven drying at $80^{\circ} \mathrm{C}$ for $48 \mathrm{~h}$. Root length was determined from a scaled photograph using LIA32 [13].

The amount of ABA in root samples was determined by modifying the standard method described by Hirai [14]. A 1-g sample of frozen root was ground and homogenized with $50 \mathrm{ml}$ of ice-cold $80 \%$ acetone, containing $10 \mathrm{mg}$ of 2, 6-di-t-butyl-4-methyl phenol as an antioxidant [15] and $0.1 \mathrm{~g}$ polyvinylpyrrolidone. The homogenized sample was filtered through a No. 5C filter, and the filtrate was purified according to Hirai [14]. ABA was quantified by HPLC (pre-column: Shin-Pack GRD-ODS, separation column: STR ODE-II, detector: UV-VIS
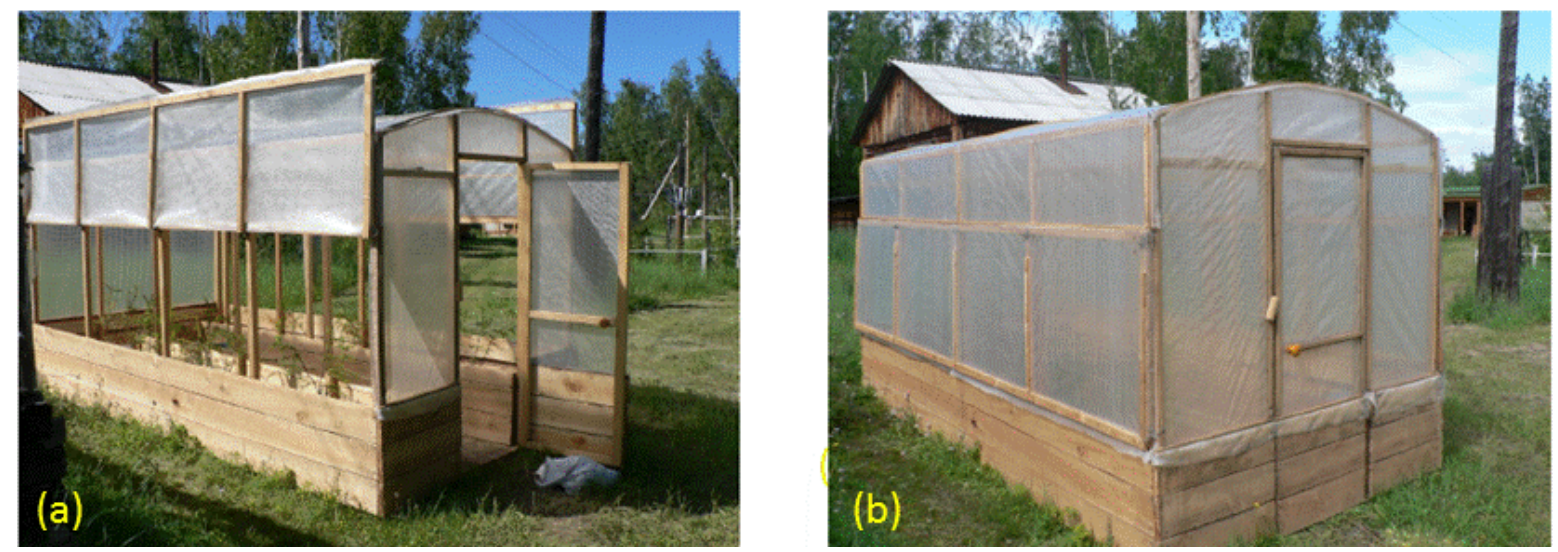

Figure 3. House for growth of seedlings during the treatment period (a) and the nontreatment period (b). 
SPD-10A at $254 \mathrm{~nm}$, analyzer CTO-10A, Shimadzu). A mixed solution of $0.1 \%$ phosphate and methanol (65:35) was used as an eluent with a $1.0 \mathrm{ml} / \mathrm{min}$ flow rate at $40^{\circ} \mathrm{C}$. The measurements were replicated three times.

For determination of biomass, aboveground and roots of seedlings were separated and washed with tap water, oven dried at $80^{\circ} \mathrm{C}$ for $48 \mathrm{~h}$, and then weighed.

\subsection{Statistical Analysis}

Differences in the data between each treatment group were assessed using Student's $t$ tests or by one-way ANOVA followed by Tukey's honestly significant difference multiple comparison test $(p<0.05)$.

\section{Results}

The volumetric soil water contents at 10 and $30 \mathrm{~cm}$ depth in the pots of each treatment measured in 2006 are summarized in Table 1. Figure 4 shows the changes in soil water content at $10 \mathrm{~cm}$ depth in the wet and dry treatments in 2007. The volumetric soil water content at $10 \mathrm{~cm}$ depth in the dry treatment decreased from $24 \%$ to 5\% over 2 months in both 2006 and 2007, whereas the content at $30 \mathrm{~cm}$ remained at 22\% in both treatments. It was confirmed that the dry treatment (watering at $20 \mathrm{~cm}$ depth) resulted in a dry condition at the surface layer.

The relative water contents in the needles of the DW and DD treatments in 2006 showed a slight but nonsignificant decrease compared with that of the WW treatment (Table 2). The concentration of ABA in the roots of the DW and DD treatments in 2006 was significantly higher than that in the roots of the WW treatment $(p<0.05$; Table 2). These results indicated that the different water treatments applied to larch seedlings led to differences in the water conditions in the rhizosphere and in the physiological conditions of roots in 2006. However, the root length per unit area was not different between the WW treatment and the DW or DD treatments (Figure 5(a)).

In the gas exchange rates obtained in June 17 and 30, the values showed no significant difference among the treatments. Figure 5(a) and Figure 5(b) shows the diurnal variations in photosynthetic rate and stomatal

Table 1. Soil water contents at $10 \mathrm{~cm}$ and $30 \mathrm{~cm}$ depth in the wet or dry treatment pots measured at the beginning and the end of 2-month treatment in 2006.

\begin{tabular}{cccc} 
& Depth $(\mathrm{cm})$ & Wet treatment (\%) & Dry treatment (\%) \\
\hline At the beginning of treatment & 10 & $21.8 \pm 1.39$ & $24 \pm 1.08$ \\
(Jun. 15) & 30 & $22.5 \pm 2.14$ & $22.5 \pm 0.89$ \\
After 2-month treatment & 10 & $23.6 \pm 1.93$ & $5.4 \pm 0.15$ \\
(Sep. 13) & 30 & $20.0 \pm 1.75$ & $23.6 \pm 0.92$ \\
\hline
\end{tabular}

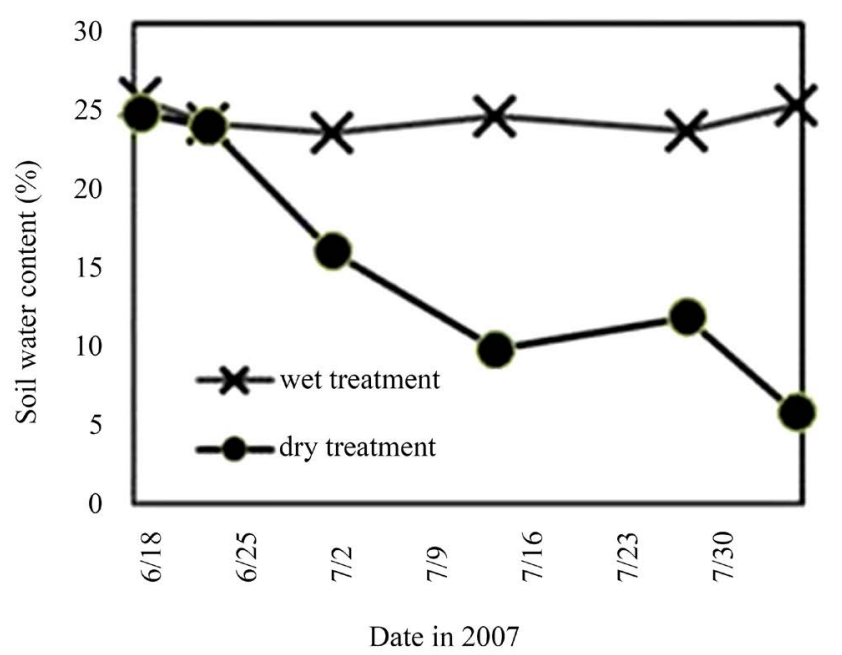

Figure 4. Change in volumetric soil water content at $10 \mathrm{~cm}$ depth of the dry treatment and wet treatment boxes measured during the treatment period in 2007. 
Table 2. Relative water content in needles and concentration of ABA in roots by wet and dry treatments in 2006.

\begin{tabular}{cc}
\hline Wet treatment $(\mathrm{WW})$ & Dry treatment (DW/DD) \\
Ave. SE & Ave. SE \\
\hline $84.0 \pm 4.2$ & $75.6 \pm 4.0$ \\
$375 \pm 46$ & $733 \pm 140^{*}$ \\
\hline
\end{tabular}

The mark* indicates a significant difference at $\mathrm{p}<0.05$.
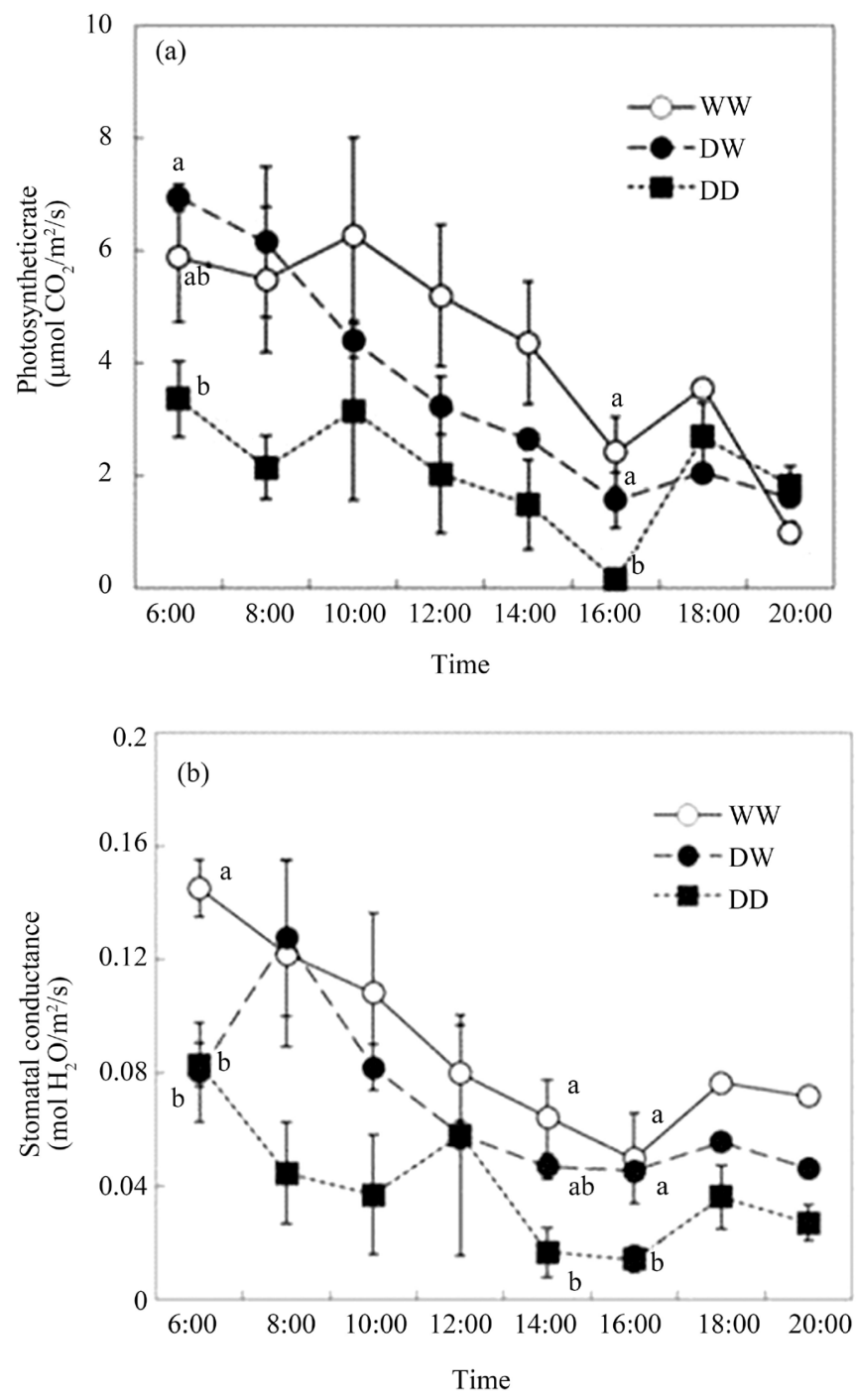

Figure 5. Gas-exchange activities of larch seedlings measured on July 2007: (a) photosynthetic rate and (b) stomatal conductance. Different letters denote significant difference at $\mathrm{p}<0.05$. The error bar shows the standard error.

conductance, respectively, measured on July 26, 2007. The values for the DD treatment were lower than those for the WW and DW treatments, with a significant difference in several data sets at 5\%. This finding clearly showed that the gas exchange rates were affected by dry conditions in 2007. Comparison between the WW and DW treatments indicated a lower trend in DW than WW in several data sets.

The total root lengths in the 0 - 15 and 15 - $30 \mathrm{~cm}$ layers measured after the treatments in August 2007 are shown in Figure 6(b). For the WW treatment, no difference in root length between the two depth layers was observed, but for the DW and DD treatments, the total root lengths in the deeper layer (15 - $30 \mathrm{~cm})$ tended to be 

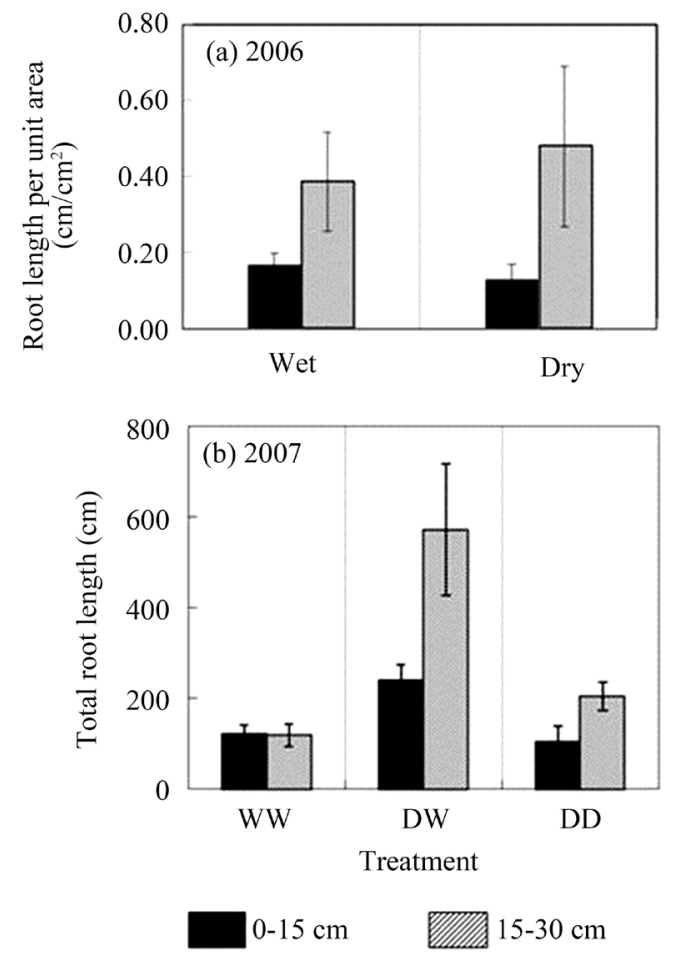

Figure 6. Root distribution in 0 - 15 and 15 - 30 cm soil layers observed in (a) 2006 and (b) 2007. For 2006, the root length observed in the cross section was shown as length per unit area (a), and for 2007 total length of root after harvest of seedlings (b). The error bar shows the standard error.

greater than those in the shallow layer $(0-15 \mathrm{~cm})$. Needle biomass and root/shoot ratio after the harvest in August 2007 are shown in Figure 7(a) and Figure 7(b), respectively. The total biomass of seedling needles was smallest in the DD and largest in the WW treatment $(p<0.01)$. The weight ratios of seedling roots to shoots were almost the same in the DW and DD treatments and significantly lower in the WW treatment.

\section{Discussion}

In the first year of the treatments, the dry condition in the soil surface layer of the DW and DD treatments caused the increase in ABA concentration in roots. Given that ABA is essential for various stress responses, such as drought [16] [17], the dry condition at the surface soil layer $(10 \mathrm{~cm})$ is expected to have stressed the seedlings, even though the soils in the deep layer $(30 \mathrm{~cm})$ contained water. However, the distribution of roots was not affected by the treatments in the first year of the treatment (Table 1).

In the second year of the treatment, the effects of the treatments on the gas exchange rates were distinct after more than one month treatment. In the data of July 26, the gas exchange rates of seedlings with the DD treatment clearly decreased comparing with the data of WW and DW treatments. Although we did not measure ABA concentrations in roots nor needles in 2007, we supposed that the ABA level would increase owing to drought stress in the same way as in 2006. ABA regulates stomatal response [18]. The results of the DW treatment showed lower photosynthetic rates and stomatal conductance than those of the WW treatment, even though the soil water conditions were the same in 2007. In other words, the physiological condition of the seedlings receiving the DW treatment fell between those of the seedlings with the DD and WW treatments. The same trend was observed in total needle biomass (Figure 6(a)). We attribute this trend to the drought stress applied in 2006 to the seedlings receiving the DW treatment. Walter demonstrated a "drought memory" in Arrhenatherum elatius by exposing plants to drought stress in different combinations using early treatment with watering or drought 

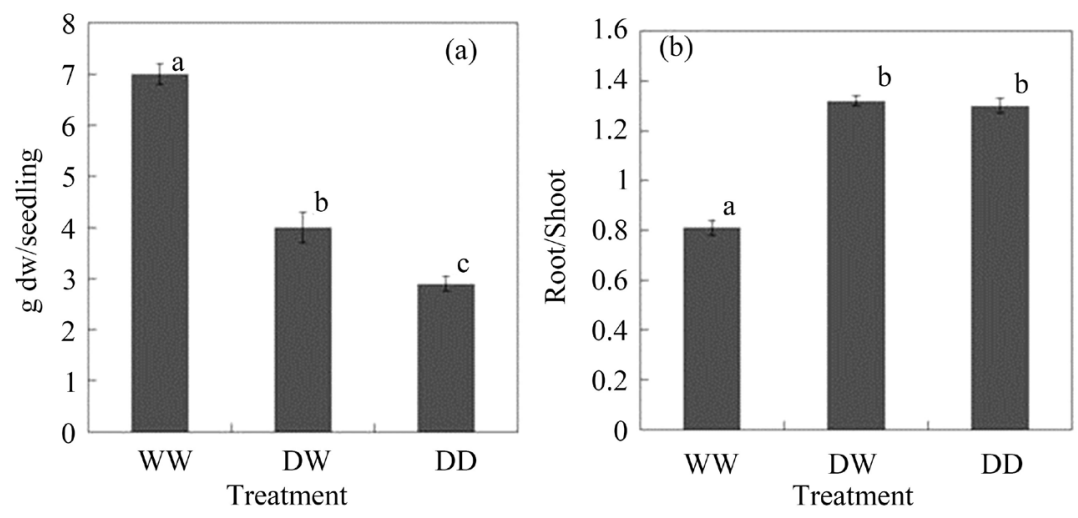

Figure 7. Effect of 2-year treatment on total biomass of needles (a) and weight ratios of root to shoot (b) of seedlings harvested on August 2007. Different letters denote significant difference at $\mathrm{p}<0.05$. The error bar shows the standard error.

within a single year [8]. Although the demonstration of "drought memory" was obtained only for herbaceous plants, it is possible to apply the phenomenon to woody plants [9]. In the present study, we suggest that the seedlings that experienced drought stress might store some memory of drought influencing their physiology in the next growing season.

The effect of dry treatment seemed to be also observed in the data for the roots of DW-treated seedlings. Whereas the roots in the WW treatment were uniformly distributed through the depth, in the DW and DD treatments, the root lengths in the deeper soil layer were greater than those in the shallower layer (Figure 6(b)). In addition, the weight ratios of seedling root to shoot were higher under the DW and DD treatments than under the WW treatment. Kajimoto reported that wetter soil conditions were unfavorable for vertical root growth of mature L. gmelinii in central Siberia [19]. Miyahara conducted a pot experiment using seedlings of L. gmelinii and found that the root/shoot ratio under drought conditions was higher than that under wet conditions [6]. The results for root distribution and root/shoot ratio of the WW treatment in the present study (Figure 6(b) and Figure 7) agree with the previous reports on the stress response of L. gmelinii. In the DW treatment, the tendencies observed in the root distribution and root/shoot ratio agreed with those in the DD treatment, even though the soil water condition in 2007 was the same as in the WW treatment. These results indicated that the growth of roots might be affected by the water condition of the previous year. This phenomenon may be related with a memory effect.

The mechanisms of the memory effect by drought stress have been investigated, and an ABA-associated mechanism has been demonstrated [7] [20]. Goh, using experimental results with ABA-entrained plants, proposed that plants have the ability to memorize stressful environmental experiences [21]. Most studies of these phenomena have been conducted from an epigenetic viewpoint [9]. A few articles have dealt with the epigenetic response of forest trees to abiotic stresses [22] [23], and change in DNA methylation has been recognized as one mechanism of epigenetic control [23]. Han and Wagner reviewed the role of chromatin in water stress response and suggested its contribution to stress memory in plants [24]. In the present study, although the replication of data were not enough and only two years observation were conducted, the obtained results suggested a possibility that the memory of drought could be stored from one growing season to the next.

In the present study, the WW treatment imitated the continuous high-precipitation years, given that the summer precipitation pattern in eastern Siberia has been changing yearly [2] [3]. The results of the WW treatment indicated that wet soil water conditions induced high photosynthetic activity and then high needle biomass and low root/shoot ratio by the pot experiment. This suggested that enough precipitation would cause a good growth of aboveground tissue of mature larch trees due to active photosynthesis in eastern Siberia. The phenomenon seemed to have a positive effect on the larch forest. However, Backhaus pointed out that the lack of drought history in a regular watering regime over years might reduce drought resistance. Our results suggest that the wet condition observed from 2005 to 2008 in eastern Siberia [2] could be a possible cause for the recent forest decline [25]. Since it is not certain whether the present results obtained through the pot experiment using seedlings could be applied to the physiology of mature trees or not, further research on the physiological response of larch trees to drastic climate change is needed to clarify mechanism of the recent decline of larch forests in eastern 
Siberia.

\section{Conclusion}

From a 2-year pot experiment using seedlings of L. cajanderi with three patterns of wet- and dry-treatment combinations under near-natural conditions in eastern Siberia, it was concluded that the soil water conditions in one growing season might influence physiological conditions and root development in the next year, although 1year treatment resulted in no significant difference in root distribution and needle water content except for the content of abscisic acid in roots between the dry and wet conditions. This phenomenon seemed to be related with a "memory effect". It is desirable to clarify the mechanism of the "memory effect" in tree species to predict the effects of climate change on forests.

\section{Acknowledgements}

This study was supported by CREST/WECNoF (PI: Prof. Takeshi Ohta, Nagoya University, Japan). The authors thank Dr. Alexander Kononov, Mr. Dimitry Suzdalov, Mrs. Nyorugyana Niolaeva, Mr. Sergey Karasanaev and Ms. Marina Trantieva for setting up the study sites and helping the research.

\section{References}

[1] Intergovermental Panel on Climate Change (IPCC) (2014) Climate Change 2014. http://www.ipcc.ch/pdf/assessment-report/ar5/syr/SYR_AR5_FINAL_full.pdf

[2] Ohta, T., Kotani, A., Iijima, Y., Maximov, T.C., Ito, S., Hanamura, M., Kononov, A.V. and Maximov, A.P. (2014) Effects of Waterlogging on Water and Carbon Dioxide Fluxes and Environmental Variables in a Siberian Larch Forest, 1998-2011. Agricultural and Forest Meteorology, 188, 64-74. http://dx.doi.org/10.1016/j.agrformet.2013.12.012

[3] Iwasaki, H., Saito, H., Kuwao, K., Maximov, T.C. and Hasegawa, S. (2010) Forest Decline Caused by High Soil Water Conditions in a Permafrost Region. Hydrology and Earth System Sciences, 14, 301-307. http://dx.doi.org/10.5194/hess-14-301-2010

[4] Yakovlev, I., Fossdal, C.G., Skroppa, T., Olsen, J.E., Jahren, A.H. and Johnsen, O. (2012) An Adaptive Epigenetic Memory in Conifers with Important Implications for Seed Production. Seed Science Research, 22, 63-76. http://dx.doi.org/10.1017/S0960258511000535

[5] Berner, L.T., Beck, P.S.A., Bunn, A.G. and Goetz, S.J. (2013) Plant Response to Climate Change along the ForestTundra Ecotone in Northeastern Siberia. Global Change Biology, 19, 3449-3462. http://dx.doi.org/10.1111/gcb.12304

[6] Miyahara, M., Takenaka, C., Tomioka, R. and Ohta, T. (2011) Root Responses of Siberian Larch to Different Soil Water Conditions. Hydrological Research Letter, 5, 93-97. http://dx.doi.org/10.3178/hrl.5.93

[7] Bruce, T.J.A., Matthes, M.C., Napier, J.A. and Pickett, J.A. (2007) Stressful "Memories" of Plants: Evidence and Possible Mechanisms. Plant Science, 173, 603-608. http://dx.doi.org/10.1016/j.plantsci.2007.09.002

[8] Walter, J., Nagy, L., Hein, R., Rascher, U., Beierkuhnlein, C., Willner, E. and Jentsch, A. (2011) Do plants Remember Drought? Hints towards a Drought-Memory in Grasses. Environmental and Experimental Botany, 71, 34-40. http://dx.doi.org/10.1016/j.envexpbot.2010.10.020

[9] Brautigam, K., Vining, K.J., Lafon-Placette, C., Fossdal, C.G., Mirouze, M., Marcos, J.G., Fluch, S., Fraga, M.F., Guevara, M.A., Abarca, D., Johnsen, O., Maury, S., Strauss, S.H., Campbell, M.M., Rohde, A., Diaz-Sala, C. and Cervera, M.T. (2013) Epigenetic Regulation of Adaptive Responses of Forest Tree Species to the Environment. Ecology and Evolution, 3, 399-415. http://dx.doi.org/10.1002/ece3.461

[10] Virlouvet, L., Ding, Y., Fujii, H., Avramova, Z. and Fromm, M. (2014) ABA Signaling Is Necessary but Not Sufficient for RD29B Transcriptional Memory during Successive Dehydration Stresses in Arabidopsis thaliana. Plant Journal, 79, 150-161. http://dx.doi.org/10.1111/tpj.12548

[11] Correia, B., Valledor, L., Meijon, M., Rodriguez, J.L., Dias, M.C., Santos, C., Canal, M.J., Rodriguez, R. and Pinto, G. (2013) Is the Interplay between Epigenetic Markers Related to the Acclimation of Cork Oak Plants to High Temperatures? Plos One, 8, e53543. http://dx.doi.org/10.1371/journal.pone.0053543

[12] Ohta, T., Maximov, T.C., Dolman, A.J., Nakai, T., van der Molen, M.K., Kononov, A.V., Maximov, A.P., Hiyama, T., Iijima, Y., Moors, E.J., Tanaka, H., Toba, T. and Yabuki, H. (2008) Interannual Variation of Water Balance and Summer Evapotranspiration in an Eastern Siberian Larch Forest over a 7-Year Period (1998-2006). Agricultural and Forest Meteorology, 148, 1941-1953. http://dx.doi.org/10.1016/j.agrformet.2008.04.012

[13] Yamamoto, K. (2005) http://www.agr.nagoya-u.ac.jp/ shinkan/LIA32/index.html 
[14] Hirai, N. (1994) Abscisic acid. In: Takahashi, N. and Masuda, Y, Eds., Handbook of Plant Hormones, Baihukan, Tokyo, 1-159. (in Japanese)

[15] Milborrow, B.V. and Mallaby, R. (1975) Occurrence of Methyl (+)-Abscisate as an Artifact of Extraction. Journal of Experimental Botany, 26, 741-748. http://dx.doi.org/10.1093/jxb/26.5.741

[16] Wilkinson, S. and Davies, W.J. (2002) ABA-Based Chemical Signalling: The Co-Ordination of Responses to Stress in Plants. Plant Cell and Environment, 25, 195-210. http://dx.doi.org/10.1046/j.0016-8025.2001.00824.X

[17] Xiong, L.M. and Zhu, J.K. (2003) Regulation of Abscisic Acid Biosynthesis. Plant Physiology, 133, 29-36. http://dx.doi.org/10.1104/pp.103.025395

[18] Chinnusamy, V., Gong, Z.Z. and Zhu, J.K. (2008) Abscisic Acid-Mediated Epigenetic Processes in Plant Development and stress Responses. Journal of Integrative Plant Biology, 50, 1187-1195. http://dx.doi.org/10.1111/j.1744-7909.2008.00727.x

[19] Kajimoto, T., Matsuura, Y., Osawa, A., Prokushkin, A.S., Sofronov, M.A. and Abaimov, A.P. (2003) Root System Development of Larix gmelinii Trees Affected by Micro-Scale Conditions of Permafrost Soils in Central Siberia. Plant and Soil, 255, 281-292. http://dx.doi.org/10.1023/A:1026175718177

[20] Virlouvet, L. and Fromm, M. (2015) Physiological and Transcriptional Memory in Guard Cells during Repetitive Dehydration Stress. New Phytologist, 205, 596-607. http://dx.doi.org/10.1111/nph.13080

[21] Goh, C.H., Nam, H.G. and Park, Y.S. (2003) Stress Memory in Plants: A Negative Regulation of Stomatal Response and Transient Induction of rd22 Gene to Light in Abscisic Acid-Entrained Arabidopsis Plants. Plant Journal, 36, 240-255. http://dx.doi.org/10.1046/j.1365-313X.2003.01872.x

[22] Harfouche, A., Meilan, R. and Altman, A. (2014) Molecular and Physiological Responses to Abiotic Stress in Forest Trees and Their Relevance to Tree Improvement. Tree Physiology, 34, 1181-1198. http://dx.doi.org/10.1093/treephys/tpu012

[23] Rico, L., Ogaya, R., Barbeta, A. and Penuelas, J. (2014) Changes in DNA Methylation Fingerprint of Quercus ilex Trees in Response to Experimental Field Drought Simulating Projected Climate Change. Plant Biology, 16, 419-427. http://dx.doi.org/10.1111/plb.12049

[24] Han, S.K. and Wagner, D. (2014) Role of Chromatin in Water Stress Responses in Plants. Journal of Experimental Botany, 65, 2785-2799. http://dx.doi.org/10.1093/jxb/ert403

[25] Backhaus, S., Kreyling, J., Grant, K., Beierkuhnlein, C., Walter, J. and Jentsch, A. (2014) Recurrent Mild Drought Events Increase Resistance toward Extreme Drought Stress. Ecosystems, 17, 1068-1081. http://dx.doi.org/10.1007/s10021-014-9781-5 